\title{
Oxidative Stress in Intoxication Type Inborn Errors of Metabolism using Thiol-Disulfide Ratio
}

\author{
Veysel Cam ${ }^{1}$, Asburce Olgac ${ }^{2}$, Mustafa Kilic ${ }^{2}$, Ozcan Erel ${ }^{3}$, Salim Neselioglu and Cigdem Seher Kasapkara ${ }^{2,4}$ \\ ${ }^{1}$ Department of Pediatrics, Dr. Sami Ulus, Maternity and Child Health, Training and Research Hospital, Ankara, Turkey \\ ${ }^{2}$ Department of Pediatric Metabolic Diseases, Dr. Sami Ulus, Maternity and Child Health, Training and Research Hospital, Ankara, \\ Turkey \\ ${ }^{3}$ Department of Biochemistry, Ankara Yildirim Beyazit University, Ankara City Hospital, Ankara, Turkey \\ ${ }^{4}$ Department of Pediatric Metabolic Diseases, Ankara Yildirim Beyazit University, Ankara, Turkey
}

\begin{abstract}
Objective: To determine the relationship of oxidative stress status with follow-up parameters, metabolic control status, and treatment compliance evaluation in patients diagnosed within toxication type inherited metabolic disease (IMDs).

Study Design: Descriptive, analytical study.

Place and Duration of Study: Dr. Sami Ulus, Maternity and Child Health, Training and Research Hospital, Ankara, Turkey, between September 2019 and March 2020.

Methodology: Sixty-seven patients, who were followed up with a diagnosis of IMDs in the pediatric metabolism outpatient clinic, and 41 healthy volunteers who applied to the social pediatrics outpatient clinic, were evaluated. Disulfide/native thiol, disulfide/total thiol, and native thiol/total thiol ratios of the patient and control group were calculated. $\mathrm{P}<0.05(*)$ value was considered significant in statistical analysis.

Results: The mean native thiol / total thiol ratio of the patient group was significantly lower when compared to the control group (92.0 \pm 3.3 vs $94.1 \pm 2.7, p=0.001)$. The median disulfide level [19.8 (11.6-25) vs $14(10.1-18.8), p=0.004]$, the mean disulfide / native thiol $(4.5 \pm 2.0$ vs $3.2 \pm 1.6, p<0.001)$ and the mean disulfide / total thiol ratios $(4.0 \pm 1.7$ vs $2.9 \pm 1.4, p=0.001)$ were higher in the patient group compared to the control group. The findings showed that oxidative stress status was increased during metabolic attacks. Poor metabolic control and non-compliance to treatment was found to be associated with increased oxidative stress. Oxidative stress parameters were found to be correlated with metabolic chemicals such as ammonia, leucine, and citrulline. There was no correlation between phenylalanine and lactate levels and oxidative stress parameters.

Conclusion: Metabolic control status and compliance with treatment are related to oxidative stress level, showing thiol/disulfide balance in urea cycle defects, phenylketonuria, and galactosemia patients.
\end{abstract}

Key Words: Thiol / disulfide, Metabolic diseases, MSUD, Galactosemia, Hyperammonemia.

How to cite this article: Cam V, Olgac A, Kilic M, Erel O, Neselioglu S, Kasapkara CS. Oxidative Stress in Intoxıcation Type Inborn Errors of Metabolism using Thiol-Disulfide Ratio. J Coll Physicians Surg Pak 2021; 31(06):663-667.

\section{INTRODUCTION}

Intoxication-type metabolic disorders (IMDs) are diseases with a progressive course that develop due to deficient and functional defects in the metabolic pathways at the enzyme and cofactor level. Acute or chronic progressive course is observed in this group of diseases following a symptom-free period interval. Although initial symptoms are usually seen in the neonatal period, they may occur in later ages or even in adulthood. Vomiting, altered consciousness, seizure, abnormal body odour, hyperammonemia, liver failure, metabolic acidosis are the most common symptoms and signs. ${ }^{1}$

Correspondence to: Dr. Asburce Olgac, Dr. Sami Ulus Children's Hospital, Division of Inborn Errors Metabolism, Ankara, Turkey

E-mail:mabolgac@yahoo.com

Received: November 18, 2020; Revised: March 30, 2021;

Accepted: May 18, 2021

DOI: https://doi.org/10.29271/jcpsp.2021.06.663
Acute attacks are often triggered by catabolism induced by infection, hunger, stress and protein intake. Phenylketonuria, organic acidemias, and urea cycle disorders are some of the common IMDs. Usually, urine organic acidanalyses, plasma, and urine amino acids, and acylcarnitine profile are used for diagnosis. ${ }^{2}$ Treatment options are dietary restriction, replacement of the missing metabolite with certain agents, addition of cofactors (e.g. vitamins), removal of toxic compounds by medical treatment (sodium benzoate, sodium phenylbutyrate, etc.) or extracorporeal detoxification, and organ transplantation. ${ }^{3}$

The contribution of oxidative stress to neurological damage in intoxication-type metabolic diseases have been discussed in the literature with different parameters in recent years. In these studies, total antioxidant level, total oxidant level, thiobarbituric acid reactive substances, malondialdehyde, antioxidant enzyme levels, urinary markers (di-tyrosine, isoprostane), dynamic thiol/disulfide balance etc. oxidative stress parameters were used to evaluate the level of oxidative stress. ${ }^{4,5}$ 
Thiols are proteins that form reversible disulfide bonds under oxidative situations. The disulfide bounds can be reduced thiol groups again; thus, thiol/disulfide homeostasis can be maintained. While thiol levels decrease under oxidative conditions, disulfide ratio increases. Dynamic thiol/disulfide homeostasis has an important role in antioxidant protection, detoxification, signal transmission, apoptosis, regulation of enzyme functions, stabilisation of protein structures, transcription and cellular signal transmission. ${ }^{6}$ The thiol/disulfide balance has not been previously investigated in patients with IMDs.

The objective of this study was to determine the relationship of oxidative stress status with metabolic control and compliance to treatment in patients diagnosed with IMDs.

\section{METHODOLOGY}

This research was conducted between September 2019 and March 2020, planned as a prospective study aiming to evaluate the thiol / disulfide balance in cases followed up with the diagnosis of intoxication type hereditary metabolic disease in the Pediatric Metabolism Unit of Dr. Sami Ulus, Maternity and Child Health, Training and Research Hospital, Ankara, Turkey. Ethics Committee approval (Reference No. 2019-086). From the electronic files of the patients; data including age, gender, consanguinity among parents, clinical findings, neurological developmentand treatments were collected.

Cases were grouped according to their diagnoses as following: Phenylalanine metabolism disorder, organic acidemias, urea cycle disorders (UCDs), and carbohydrate metabolism disorders. Some patients with various diagnoses were grouped as other (including maple syrup urine disease (MSUD), tyrosinemia and nonketotic hyperglycinemia). Compliance to treatment was evaluated using the main laboratory parameters that are used for the follow-up of the specific disease (e.g., phenylalanine level for phenylalanine metabolism disorders, leucinefor MSUD.

Cases were grouped as good and poor in terms of compliance to treatment and metabolic control status. Poor metabolic control was defined as the increase in laboratory parameters that are known to be toxic in a specific disease (phenylalanine for phenylketonuria and hyperphenylalaninemia, ammonia for urea cycle disorders, reducing substance in urine for carbohydrate metabolism disorders, glycine for nonketotic hyperglycinemia). In terms of developmental steps, they were grouped as normal or delayed when compared with their peers.

Thiol-disulfide parameters were determined by automatic measurement method developed by Erel and Neselioglu. ${ }^{7}$ Dynamic disulfide level was estimated by following formula: Dynamic disulfide level: (total thiol-native thiol)/2. After measuring of native thiol, total thiol and disulfide amount, disulfide: total thiol ( $\mathrm{SS} / \mathrm{SH}+\mathrm{SS})$, disulfide: native thiol (SS/SH) and native thiol: total thiol $(\mathrm{SH} / \mathrm{SH}+\mathrm{SS})$ are expressed as percent ratio of oxidant and antioxidant groups. The increase in disulfide and decrease in native thiol was an indicator of oxidativestress.
Statistical analysis was performed using the Statistical Package for Social Sciences (SPSS) for Windows 22 (IBM Corp., Armonk NY, USA) programme. Whether the distribution of continuous variables were normal or not was determined by Shapiro-Wilk test. Unless specified otherwise, continuous data were described as mean \pm SD for normal distributions, and median (percentile 25-percentile 75) for skewed distributions. Statistical analysis differences in normally distributed variables between two independent groups were compared by Student's ttest. Mann-Whitney U-test were applied for comparisons of the not normally distributed data. One-way ANOVA test (posthoc: Bonferroni) was used for the comparison of numerical variables with normal distribution between three and more groups, and Kruskal-Wallis H-test (posthoc: Dunn-Bonferoni) was used in the comparison of numerical variables that did not show normal distribution. Chi-square and Fisher's Exact Chi-square tests were used for comparison of categorical data. Categorical data were described as number of cases (\%). The relationship between numerical variables was evaluated using Spearman correlation analysis. $p<0.05(*)$ value was considered significant.

\section{RESULTS}

Sixty-seven patients, who were followed up with a diagnosis of intoxication-type metabolic diseases in the pediatric metabolism outpatient clinic and 41 healthy volunteers who applied to the social pediatrics outpatient clinic were included in the study. Thirty (44.8\%) of the cases were male and 37 (55.2\%) were female. The parents of $71.6 \%$ of the cases ( $n: 48)$ were consanguineous, and $32.8 \%$ ( $n: 22$ ) had a family history of metabolic disease. Neurological development was found to be deteriorated in $49.3 \%$ ( $n: 33$ ) of the cases. The diagnoses of patients enrolled in the study are shown in Tablel.

Table I: Diagnoses of the cases enrolled in the study.

\begin{tabular}{|l|l|l|}
\hline Diagnoses & $\begin{array}{l}\text { Population } \\
\mathbf{n = 6 7} \mathbf{n ( \% )}\end{array}$ & $\begin{array}{l}\text { Subgroup } \\
\mathbf{n ( \% )}\end{array}$ \\
\hline Aminoacid metabolism disorders & $\mathbf{1 4 ( 2 0 . 9 )}$ & \\
\hline Nonketotic hyperglycinemia & $4(6.0)$ & $4(28.6)$ \\
\hline Maple syrup urine Disease & $7(10.4)$ & $7(50.0)$ \\
\hline Tyrosinemia type1 & $3(4.5)$ & $3(21.4)$ \\
\hline Phenylalanine metabolism disorders & $\mathbf{1 9 ( 2 8 . 4 )}$ & \\
\hline Hyperphenylalaninemia & $6(9.0)$ & $6(31.6)$ \\
\hline Tetrahydrobiopterin metabolism disorders & $1(1.5)$ & $1(5.3)$ \\
\hline Classical phenylketonuria & $12(17.9)$ & $12(63.1)$ \\
\hline $\begin{array}{l}\text { Galactosemia (Carbohydrate metabolism } \\
\text { disorders) }\end{array}$ & $6(9.0)$ & $6(100.0)$ \\
\hline Organic acidemia & $\mathbf{1 7 ( 2 5 . 4 )}$ & \\
\hline Glutaricaciduria type 1 & $3(4.5)$ & $3(17.6)$ \\
\hline İsovalericacidemia & $2(3.0)$ & $2(11.8)$ \\
\hline Methylmalonicacidemia & $6(9.0)$ & $6(35.3)$ \\
\hline Propionic acidemia & $6(9.0)$ & $6(35.3)$ \\
\hline Urea cycle disorders & $\mathbf{1 1 ( 1 6 . 4 )}$ & \\
\hline Argininemia & $1(1.5)$ & $1(9.1)$ \\
\hline Arginosuccinic aciduria & $\mathbf{1 ( 1 . 5 )}$ & $1(9.1)$ \\
\hline $\begin{array}{l}\text { Carbamoyl phosphate synthetase I } \\
\text { deficiency }\end{array}$ & $1(1.5)$ & $1(9.1)$ \\
\hline Ornithine transcarbamylase deficiency & $2(3.0)$ & $2(18.2)$ \\
\hline Citrullinemia type 1 & $6(9.0)$ & $6(54.5)$ \\
\hline
\end{tabular}


Table II: Thiol analyses of subgroups of IMDs.

\begin{tabular}{|c|c|c|c|c|c|c|c|}
\hline & $\begin{array}{l}\text { Control } \\
(n=41)^{(a)}\end{array}$ & $\begin{array}{l}\text { Aminoacid metabolism } \\
\text { disorders } \\
(n=14)^{(b)}\end{array}$ & $\begin{array}{l}\text { Phenylalanine } \\
\text { metabolism } \\
\text { disorders } \\
(\mathbf{n = 1 9})^{(\mathrm{c})}\end{array}$ & $\begin{array}{l}\text { Galactosemia } \\
\qquad(n=6)^{(d)}\end{array}$ & $\begin{array}{c}\text { Organic } \\
\text { acidemia } \\
(n=17)^{(e)}\end{array}$ & $\begin{array}{l}\text { Urea cycle disorders } \\
\qquad(n=11)^{(f)}\end{array}$ & p-value \\
\hline $\begin{array}{l}\text { Disulfide } \\
(\mu \mathrm{mol} / \mathrm{L})\end{array}$ & $\begin{array}{c}12.0 \\
(10.1-18.8)^{(\mathrm{e})}\end{array}$ & $\begin{array}{c}17.1 \\
(11.6-22.8)\end{array}$ & $\begin{array}{c}19.2 \\
(11.6-23.5)\end{array}$ & $\begin{array}{c}10.3 \\
(7.1-16.6)^{(\mathrm{e})}\end{array}$ & $\begin{array}{c}25 \\
(17.5-28.5)^{(a, d)}\end{array}$ & $\begin{array}{c}21.8 \\
(12.4-31.3)\end{array}$ & $0.002 *$ \\
\hline $\begin{array}{l}\text { Disulfide/ } \\
\text { native thiol \% }\end{array}$ & $\begin{array}{c}3.1 \\
(2.0-3.8)^{(\mathrm{e})}\end{array}$ & $\begin{array}{l}3.8 \\
(2.5-5.1)\end{array}$ & $\begin{array}{c}4.1 \\
(2.7-5.3)\end{array}$ & $\begin{array}{c}2.4 \\
(1.4-3.5)^{(\mathrm{e})}\end{array}$ & $\begin{array}{c}5.9 \\
(4.7-6.9)^{(\mathrm{a}, \mathrm{d})}\end{array}$ & $\begin{array}{c}4.8 \\
(2.5-6.4)\end{array}$ & $<0.001^{*}$ \\
\hline $\begin{array}{l}\text { Disulfide/ } \\
\text { total thiol } \\
\%\end{array}$ & $\begin{array}{c}2.9 \\
(1.9-3.6)^{(\mathrm{e})}\end{array}$ & $\begin{array}{c}3.6 \\
(2.4-4.6)\end{array}$ & $\begin{array}{c}3.8 \\
(2.6-4.8)\end{array}$ & $\begin{array}{c}2.3 \\
(1.4-3.3)^{(\mathrm{e})}\end{array}$ & $\begin{array}{c}5.3 \\
(4.3-6.0)^{(a, d)}\end{array}$ & $\begin{array}{c}4.4 \\
(2.4-5.6)\end{array}$ & $<0.001^{*}$ \\
\hline $\begin{array}{l}\text { Native thiol/ } \\
\text { total thiol\% }\end{array}$ & $94.1 \pm 2.7^{(\mathrm{e})}$ & $92.7 \pm 3.1$ & $92.7 \pm 3.0^{(\mathrm{e})}$ & $94.2 \pm 2.2^{(\mathrm{e})}$ & $89.6 \pm 2.7^{(\mathrm{a}, \mathrm{c}, \mathrm{d})}$ & $92.8 \pm 3.7$ & $<0.001 *$ \\
\hline
\end{tabular}

Values in the Table are shown as median $\left(25^{\text {th }}-75^{\text {th }}\right.$ percentiles). Superscripts $(a, b, c, d$, e \& $f)$ are indicating the significant difference b/w groups.

Table III: Relationship between metabolic markers and thiol / disulfide parameters.

\begin{tabular}{|c|c|c|c|c|c|}
\hline & & $\begin{array}{l}\text { Disulfide } \\
(\mu \mathrm{mol} / \mathrm{L})\end{array}$ & $\begin{array}{c}\text { Disulfide/native } \\
\text { thiol } \%\end{array}$ & Disulfide/total thiol\% & Native thiol/total thiol\% \\
\hline Ammonia & $\begin{array}{l}\mathrm{r} \\
\mathrm{p}\end{array}$ & $\begin{array}{l}0.536 \\
<0.01\end{array}$ & $\begin{array}{l}0.538 \\
<0.05^{*}\end{array}$ & $\begin{array}{l}0.538 \\
<0.05^{*}\end{array}$ & $\begin{array}{l}-0.538 \\
<0.05^{*}\end{array}$ \\
\hline Lactate & $\begin{array}{l}r \\
p\end{array}$ & $\begin{array}{c}-0.310 \\
0.303\end{array}$ & $\begin{array}{c}-0.235 \\
0.439\end{array}$ & $\begin{array}{c}-0.235 \\
0.439\end{array}$ & $\begin{array}{l}0.235 \\
0.439\end{array}$ \\
\hline Citrulline & $\begin{array}{l}r \\
p\end{array}$ & $\begin{array}{l}0.400 \\
0.505\end{array}$ & $\begin{array}{l}0.900 \\
<0.05^{*}\end{array}$ & $\begin{array}{l}0.900 \\
<0.05^{*}\end{array}$ & $\begin{array}{l}-0.900 \\
<0.05^{*}\end{array}$ \\
\hline Phenylalanine & $\begin{array}{l}\mathrm{r} \\
\mathrm{p}\end{array}$ & $\begin{array}{l}0.088 \\
0.721\end{array}$ & $\begin{array}{l}0.232 \\
0.340\end{array}$ & $\begin{array}{l}0.270 \\
0.263\end{array}$ & $\begin{array}{l}-0.270 \\
0.263\end{array}$ \\
\hline Leucine & $\begin{array}{l}r \\
p\end{array}$ & $\begin{array}{l}0.607 \\
<0.05^{*}\end{array}$ & $\begin{array}{l}0.929 \\
<0.01^{*}\end{array}$ & $\begin{array}{l}0.929 \\
<0.01 *\end{array}$ & $\begin{array}{l}-0.929 \\
<0.01 *\end{array}$ \\
\hline
\end{tabular}

The mean native thiol / total thiol ratio of the patient group was significantly lower when compared to the control group $(92.0 \pm 3.3$ vs $94.1 \pm 2.7, p=0.001)$. Moreover, the median disulfide level [19.8 (11.6-25) vs. 14(10.1-18.8), $p=0.004$, the mean disulfide / native thiol $(4.5 \pm 2.0$ vs. $3.2 \pm 1.6$, $p<0.001)$ and the mean disulfide / total thiol ratios $(4.0 \pm 1.7$ vs. $2.9 \pm 1.4, p=0.001$ ) were higher in the patient group compared to the control group.

Among the patient group, $38.8 \%$ ( $n: 26)$ had poor metabolic control. The rate of those with poor neurological development was found to be higher in patients with poor metabolic control compared to those with good control [20(76.9\%) vs. $13(31.7 \%) ; p<0.001]$. The rate of noncompliance to treatment was $37.3 \%$ ( $n: 25)$. In patients with treatment noncompliance, the rate of neurological deterioration was higher than patients who followed the therapeutic regimen [20(80\%) vs. $13(31 \%) p<0.001]$.

The median disulfide level, the median disulfide / native thiol ratio and the median disulfide / total thiol ratio were found to be higher in organic acidemia group compared to other patient groups and control group. When the patients were evaluated according to their diagnoses, it was seen that, the mean native thiol / total thiol ratio was significantly lower in the organic acidemia group compared to the other disease groups (Table II).

In the cases with poor metabolic control, the mean native thiol / total thiol ratio was significantly low $(90.3 \pm 3.2 \mathrm{vs}$. $93.1 \pm 3.0, p=0.001)$, the mean disulfide level $(24.2 \pm 10.7$ vs.17.3 $\pm 7.8, p=0.004)$, the mean disulfide / native thiol (5.4 \pm 1.9 vs. $3.8 \pm 1.7, p=0.001$ ), and mean disulfide / total thiol ratios were higher $(4.8 \pm 1.6$ vs. $3.5 \pm 1.5, p=0.001)$.

Native thiol / total thiol ratio was found to be low in cases that did not comply with treatment. The disulfide level, median disulfide / native thiol and disulfide / total thiol ratios did not differ significantly. 
The correlation between ammonia level and thiol/disulfide balance was investigated in 24 patients. Ammonia level was found to correlate with disulfide level, disulfide / native thiol ratio and disulfide / total thiol ratio $(r=0.536 ; p=0.007, r=$ $0.508 ; p=0.011, p=0.508$; and $p=0.011$, respectively). There was a negative correlation between native thiol / total thiol ratio and ammonia level $(r=-0.508 ; p=0.011)$.

A positive correlation was found between disulfide / native thiol and disulfide / total thiol ratios and leucine levels in 7 patients with MSUD included in our study $(r=0.929$, $p=0.003$; and $r=0.929, p=0.003$, respectively). There was a negative correlation between native thiol/ total thiol ratio ( $r$ $=-0.929 ; p=0.003$ ) and leucinelevels.There were no significant relationship with disulfide / thiolparameters, and phenylalanine and lactate levels (Table III).

\section{DISCUSSION}

Oxidative stress is known to be related with the pathogenesis of several inborn errors of metabolism (IEMs). Many markers of oxidative stress have been documented to rise in especially intoxication-type metabolic disorders. ${ }^{4-7}$

In this study, the change in thiol / disulfide parameters compared to the control group was evaluated. In addition, the relation of demographic characteristics, metabolic control status, treatment compliance, and follow-up parameters (ammonia, lactate, citrulline, phenylalanine, leucine) with thiol/disulfide parameters were assessed.

In the literature, there are few studies in which oxidative stress was evaluated by thiol / disulfide balance in metabolic diseases. In the study by Cansever et al, ${ }^{8}$ within patients with L-2-hydroxyglutaric aciduria, the effect of antioxidant treatment on thiol/disulfide parameters was investigated. Fourteen of the cases were included in the study that receiving antioxidant treatment, and there was no significant difference in terms of thiol / disulfide parameters compared to the control group. The authors suggested that the antioxidant treatment prevented oxidative damage. Zubarioglu et al. investigated thiol / disulfide balance in patients with MSUD that were metabolically controlled, and showed that there was no significant difference compared to the control group. ${ }^{9}$

In the study of McGuire et al., ${ }^{10}$ a correlation was found between the clinical status of the cases with metabolic disorders and oxidative stress parameters. In this study, the median disulfide level, median disulfide / native thiol, and median disulfide / total thiol ratio were found to be higher in cases with poor metabolic control, and mean native thiol / total thiol ratio was found to be significantly lower, suggesting oxidative stress. Also, the mean native thiol / total thiol ratio was found to be significantly lower in the cases with treatment non-compliance. It was observed that metabolic control status and treatment compliance were associated with thiol / disulfide parameters.
Hyperammonemia, that is a primary symptom in many IMDs (especially urea cycle disorders) can cause cortical atrophy, ventricular dilation, and demyelination in the central nervous system, which develops by disrupting nitric oxide metabolism and increased oxidative stress, leading to permanent brain damage. ${ }^{11}$ It is understood that hyperammonemia in rats affects astrocytes by creating oxidative stress and causes increased proteasome activity. ${ }^{12}$ Kosenko et al. have shown that, hyperammonemia increases superoxide production; and reduces the activities of antioxidant enzymes such as glutathione peroxidase, superoxide dismutase, and catalase. ${ }^{13}$ In accordance with these findings, in this study, ammonia level was found to correlate with disulfide level, disulfide / native thiol ratio and disulfide / total thiol ratio. There was a negative correlation between native thiol / total thiol ratio and ammonia level.

It has been suggested that oxidative stress may be associated with neurological findings in citrullinemia. Prestes et al. showed that citrulline accumulation reduced antioxidant capacity. ${ }^{14}$ A positive correlation was found between the disulfide / native thiol ratio and the disulfide / total thiol ratio and the citrulline level in our study. Also, a negative correlation between native thiol/ total thiol ratio and citrulline level was detected. These results highlight the increase in citrulline as an independent risk factor leading to oxidative stress.

Scaini et al. showed that the accumulation of branchedchain amino acids causes DNA damage by increasing free oxygen radicals and this effect can be limited by antioxidant therapy. ${ }^{15}$ In the study conducted by Zubarioğlu et al. with 20 patients with good metabolic control of MSUD, in which they evaluated oxidative stress with thiol / disulfide parameters, no statistically significant difference was found in terms of thiol / disulfide balance compared to the control group. ${ }^{9}$ The present results are consistent with the results of the study in which Zubarioğlu et al., emphasised the importance of metabolic control in preventing oxidative stress.

Oxidative stress is known results from mitochondrial dysfunction and has been proposed as a prime cause of the pathogenesis that occurs in many IEMs. ${ }^{16}$ Previous studies on IEMs patients have found elevated levels of lipid peroxidation and decreased antioxidant capacity. ${ }^{17,18}$ The importance of lowering oxidative stress in promoting health and reducing the burden of disease, and the antioxidant therapy as a treatment option for many IMDs have been previously stressed in many studies. ${ }^{19-22}$

\section{CONCLUSION}

This study reveals that thiol-disulfide balance is impaired in intoxication-type metabolic diseases, and oxidant-antioxidant balance is associated with treatment compliance and good metabolic control. This study sheds a light to the underlying mechanism of IMDs, that may be guiding in the novel treatment strategies of these disorders. 


\section{ETHICAL APPROVAL:}

Ethical approval was obtained from the Ethics Committee of Ankara Dışkapı Hematology and Oncology Hospital, prior to initiation of the research work.

\section{PATIENTS' CONSENT:}

Informed consents have been obtained from all patients to publish the data concerning this study.

\section{CONFLICT OF INTEREST:}

The authors declared no conflict of interest.

\section{AUTHORS' CONTRIBUTION:}

VC, OE: Conception and design of work, the analysis and interpretation of data.

$\mathrm{AO}, \mathrm{SN}$ : Conception of work, drafting of work, final approval of theversion to be published.

MK, CSK: Design of work, revision of work, final approval of the version to be published.

\section{REFERENCES}

1. Ellaway C, Wilcken B, Christodoulou J. Clinical approach to inborn errors of metabolism presenting in the newborn period. J Paediatrics Child Health 2002; 38(5):511-7.doi: 10.1046/j.1440-1754.2002.00047.x.

2. Batshaw ML, Tuchman M, Summar M, Seminara J. A longitudinal study of urea cycle disorders. Mol Genet Metab 2014; 113(1-2):127-30. doi:10.1016/j.ymgme.2014. 08.001.

3. Ezgu F. Inborn errors of metabolism. Adva Clin Chem 2016; 73:195-250.doi: 10.1016/bs.acc.2015.12.001.

4. Ercal N, Aykin-Burns N, Gurer-Orhan H, McDonald JD. Oxidative stress in a phenylketonuria animal model. Free RadicBiol Med 2002; 32(9):906-11.doi: 10.1016/s0891- 5849(02) 00781-5.

5. Nordgren M, Fransen M. Peroxisomal metabolism and oxidative stress. Biochimie 2014; 98:56-62.doi: 10.1016/ j.biochi.2013.07.026.

6. Devasagayam T, Tilak J, Boloor K, Sane KS, Ghaskadbi SS, Lele $R$. Free radicals and antioxidants in human health: current status and future prospects. J Assos Physicians India 2004;52:794-804.

7. Erel O. A novel automated method to measure total antioxidant response against potent free radical reactions. Clin Biochem 2004; 37(2):112-9.doi: 10.1016/j.clinbio chem. 2003.10.014.

8. Cansever MS, Zubarioglu T, Oruc C, Kiykim E, Gezdirici A, Neselioglu $S$, et al. Oxidative stress among L-2-hydroxyglutaric aciduria disease patients: Evaluation of dynamic thiol/disulfide homeostasis. Metabolic Brain Dis 2019; 34(1): 283-8.doi: 10.1007/s11011-018-0354-8.

9. Zubarioglu T, Kiykim E, Cansever MS, Neselioglu S, AktugluZeybek C, Erel O. Evaluation of dynamic thiol/disulfide homeostasis as a novel indicator of oxidative stress in maple syrup urine disease patients under treatment. Metabolic Brain
Dis2017; 32(1):179-84.doi: 10.1007/ s11011- 016-9898-7.

10. McGuire PJ, Parikh A, Diaz GA. Profiling of oxidative stress in patients with inborn errors of metabolism. Molecular Genetics Metabolism 2009; 98(1-2):173-80.doi: 10.1016/j.ymgme.2009.06.007.

11. Cagnon L, Braissant O. Hyperammonemia-induced toxicity for the developing central nervous system. Brain Res Rev 2007; 56(1):183-97.doi: 10.1016/j.brainresrev.2007. 06.026.

12. Widmer R, Kaiser B, Engels M, Jung T, Grune T. Hyperammonemia causes protein oxidation and enhanced proteasomal activity in response to mitochondria-mediated oxidative stress in rat primary astrocytes. Archives BiochemBiophys 2007; 464(1):1-11.doi: 10.1016/ j.abb.2007.03.027.

13. Kosenko E, Kaminsky M, Kaminsky A, Valencia M, Lee L, Hermenegildo C, et al. Superoxide production and antioxidant enzymes in ammonia intoxication in rats. Free Radi Res1997; 27(6):637-44.doi: 10.3109/1071576970 9097867.

14. Prestes CC, Sgaravatti AM, Pederzolli CD, Sgarbi MB, Zorzi GK, Wannmacher CM, et al.Citrulline and ammonia accumulating in citrullinemia reduces antioxidant capacity of rat brain in vitro. Metabolic Bra Dis 2006; 21(1):63-74.doi: 10.1007/s11011-006-9005-6.

15. Scaini G, Jeremias IC, Morais MO, Borges GD, Munhoz BP, Leffa DD, et al. DNA damage in an animal model of maple syrup urine disease. Mole Gene Metab 2012; 106(2): 169-74.doi: 10.1016/j.ymgme.2012.04.009.

16. Wajner M, Latini A, Wyse AT, Dutra-Filho CS. The role of oxidative damage in the neuropathology of organic acidurias: insights from animal studies. J Inherit Metab Dis 2004; 27(4):427-48.doi: 10.1023/B:BOLI.0000 037353.13085.e2.

17. Barschak AG, Sitta A, Deon M, Barden AT, Dutra-Filho CS, Wajner $\mathrm{M}$, et al. Oxidative stress in plasma from maple syrup urine disease patients during treatment. Metab Brain Dis 2008; 23(1):71-80.doi: 10.1007/s11011-007-9077-y.

18. Barschak AG, Sitta A, Deon M, Oliveira M, Haeser A, Wajner $M$, et al. Evidence that oxidative stress is increased in plasma from patients with maple syrup urine disease. Metab Brain Dis 2006; 21(4):279-86.doi: 10.1007/s11011-006-9030-5.

19. Bridi R, Braun CA, Zorzi GK, Wannmacher C, Wajner M, Lissi $E$, et al. Alpha-keto acids accumulating in maple syrup urine disease stimulate lipid peroxidation and reduce antioxidant defense in cerebral cortex from young rats. Metab Brain Dis 2005; 20(2):155-67.doi: 10.1007/ s11011-005-4152-8.

20. Pettenuzzo LF, Schuck PF, Fontella F, Wannmacher C, Wyse AT, Netto CA, et al. Ascorbic acid prevents cognitive deficits caused by chronic administration of propionic acid to rats in the water maze. Pharmacol Biochem Behav 2002; 73(3):623-29.doi: 10.1016/s0091-3057(02)00856-0.

21. Garcia MV, Lopez-Mediavilla C, Juanes de la Pena MC, Medina JM. Antioxidant defence of the neonatal rat brain against acute hyperammonemia. Brain Res 2004; 1001(1-2): 159-63.doi: 10.1016/j.brainres.2003.12.010.

22. Andersson HC, Marble M, Shapira E. Long-term outcome in treated combined methylmalonicacidemia and homocystinemia. Genet Med 1999; 1(4):146-150.doi: 10.1097/ 00125817-199905000-00006. 